\title{
Special Systems Theory
}

\author{
Kent D. Palmer \\ http://kdp.me \\ kent@palmer.name \\ $\underline{714-633-9508}$ \\ Copyright 2013 Kent Palmer; Draft 0.7, 2013.4.8, reworked 2013.6.21 \\ All rights reserved. Not for distribution \\ CAS20130621paperkdp07a.docx \\ http://kentpalmer.name
}

\begin{abstract}
A new advanced systems theory concerning the emergent nature of the Social, Consciousness, and Life based on Mathematics and Physical Analogies is presented. This metatheory concerns the distance between the emergent levels of these phenomena and their ultraefficacious nature. The theory is based on the distinction between Systems and Meta-systems (organized Openscape environments). We first realize that we can understand the difference between the System and the Meta-system in terms of the relationship between a 'Whole greater than the sum of the parts' and a 'Whole less than the sum of its parts', i.e., a whole full of holes (like a sponge) that provide niches for systems in the environment. Once we understand this distinction and clarify the nature of the unusual organization of the Meta-system, then it is possible to understand that there is a third possibility which is a whole exactly equal to the sum of its parts that is only supervenient like perfect numbers. In fact, there are three kinds of Special System corresponding to the perfect, amicable, and sociable aliquot numbers. These are all equal to the sum of their parts but with different degrees of differing and deferring in what Jacques Derrida calls "differance". All other numbers are either excessive (systemic) or deficient (metasystemic) in this regard. The Special Systems are based on various mathematical analogies and some physical analogies. But the most important of the mathematical analogies are the hypercomplex algebras, which include the Complex Numbers, Quaternions, and Octonions, with the Sedenions corresponding to the Emergent Meta-system. However, other analogies are the Hopf fibrations between hyperspheres of various dimensions, nonorientable surfaces, soliton solutions, etc. These Special Systems have a long history within the tradition since they can be traced back to the imaginary cities of Plato. The Emergent Meta-system is a higher order global structure that includes the System with the three Special Systems as a cycle. An example of this from our tradition is in the Monadology of Gottfried Wilhelm von Leibniz. There is a conjunctive relationship between the System schema and the Special Systems that produce the Meta-system schema cycle. The Special Systems are a meta-model for the relationship between the emergent levels of Consciousness (Dissipative Ordering based on the theory of negative entropy of Prigogine), Living (Autopoietic Symbiotic based on the theory of Maturana and Varela), and Social (Reflexive based on the theory of John O'Malley and Barry Sandywell). These different special systems are related to the various existenitals identified by Martin Heidegger in Being and Time and various temporal reference frames identified by Richard M. Pico. We also relate the special systems to morphodynamic and teleodynamic systems of Terrence Deacon in Incomplete Nature to which we add sociodynamic systems to complete the series of Special Systems.
\end{abstract}

Keywords: Hypercomplex Algebras, Hopf Fibrations, Hyperspheres, Special Systems, Systems Theory, Autopoiesis, Dissipative Structures, Reflexive Systems, Social Theory, Sociology, Consciousness, Life, Meta-systems, OpenScapes, Emergence, Solitons, Breathers, Mobius Strips, 
Kleinian Bottles, Aliquot Numbers, Hopf Fibration, Hyperspheres, Heidegger, Existentials, Temporality, Morphodynamic, Teleodynamic, ententional, absential phenomena

General Schemas Theory - General Schemas Theory ${ }^{1}$ posits that there are ten schemas that are projected in a Kantian style but not in a homogeneous and objective separated space and time. Instead, there are Mathematical and Geometric schemas, as Umberto Eco refers to them in Kant and the Platypus, that organize different scopes of spacetime as templates of understanding that are projected ontologically on ontic emergent thresholds. These schemas include: Pluriverse, Kosmos, World, Domain, Openscape (meta-system), System, Form, Pattern, Monad, and Facet. The rule of the $S^{\prime}$ (prime schema) hypothesis in General Schemas Theory is that there are two schemas per dimension and two dimensions per schema. Thus, there are ten schemas that stretch from -1 dimension to the $9^{\text {th }}$ dimension. Beyond that, in the $10^{\text {th }}$ dimension there is unschematized string theory followed by $\mathrm{M}$ theory and $\mathrm{F}$ theory in the $11^{\text {th }}$ and $12^{\text {th }}$ dimensions. Unschematized dimensions mean that we have no ready template to understand what exists at those dimensions. This assumes that schemas help us to comprehend what is happening with respect to dimensions up to the tenth dimension, i.e., schemas help us comprehend higher dimensional space, but only so far, and fall short of helping us to understand string theory. $\mathrm{F}$ theory has the peculiarity that it spawns two orthogonal time lines, which is particularly difficult for us to comprehend within the compass of the Metaphysical era. The center of the ring of the schemas consists of two schemas for the System and the Meta-system that share the fourth dimension between them. Systems and Meta-systems are inverse duals of each other. The Metasystem is the organized environment, the ecology, the context, the medium, or the situation within which the system schema appears. We interpret Systems to be the conceptual analog of perceptual gestalts. Their dual is Process, which is the conceptual analog of perceptual flows. Gestalts are 'figure on ground' while Flows take the figure and push it into the background to become a reference point for looking at the flowing background, which has now become a foreground. The key aspect of a System is that it is emergent and thus a 'whole greater than the sum of its parts'. This means a Meta-system is a 'whole less than the sum of its parts', i.e., a whole full of holes (like a sponge), which means that, as an ecosystem, it offers up niches for systems to fit into. Meta-systems act as filters for Systems. Since their niches are perfectly fitted to the Systems that may inhabit them, they select out the systems that are adapted to exist within a given niche. The ability of Systems to take shocks within the environment of the meta-system and bounce back is called resilience. The ability of a System to change in order to fit with a changing environment, or fit better into an existing environment, is called adaptability. The ability of a System to change from one niche (for which it is optimized) to another niche, is called Transformation. Systems and Meta-systems may both be formalized by Turing Machines and the relationship between them is like an application in its "operating [meta-]system" environment. The meta-system provides resources for the system. The meta-system has an organization that is complementary to that of the system. This is opposed to thinking of the system as if it has a background that is a homogeneous plenum with no organization. Meta-systems are not a collection of systems that would give us a "system of systems" (super-system), which would merely raise the system schema to the next higher level of abstraction. Meta-systems have a fundamentally different essential organization from that of Systems. Meta-systems and Systems are nested and interleaved in their nesting. Each set of systems is within an operating environment of the meta-system that exists within the super-system that encases them. Systems are like nested bubbles (like Russian Dolls) and the meta-systems are like the spaces between these bubbles, but instead of being just spaces they have their own inverse dual organization to that of the Systems they contain. Together the system and meta-system are entropic. The system is an example of an

1 "From General Systems Theory to General Schemas Theory" by author ISSS 2004. See http://archonic.net 
elliptical geometrical space and the meta-system is an example of a hyperbolic geometrical space of non-Euclidian geometry. We associate this entropic basis with the physical reference frame of Einsteinian Relativity, as does Pico. In terms of the existentialia of Heidegger's Dasein in Being and Time we associate this fibration with the existential of "Falling", which is associated with Ambiguity, Curiosity, and Idle-talk that are the degenerate modes of the other existenitals of Dasein associated with the Present as an ecstatic horizon, and this is related to theromdynamics, which gives the fundamental basis for negative entropy within 'far from equilibrium' systems. In the present, thermodyanmics is always acting and is experienced as "Falling" by Dasein through the degeneration of the other existentials.

Special Systems Theory - If there are emergent wholes greater than the sum of their parts, and de-emergent wholes less than the sum of their parts, then the other possibility would be wholes exactly equal to the sum of their parts, which are perfectly supervenient. An example of this is the perfect number whose total is precisely the sum of its divisors. These types of numbers are very rare. It turns out that there are three types of Special Systems that correspond to the perfect, amicable, and sociable aliquot numbers. All other numbers are excessive or deficient with respect to the comparison of the sum of the divisors and the totality of the number. Special Systems are defined by multiple mathematical and physical anomalies whose various features fit together to give us a picture of what these special systems might be like. Examples of these mathematical analogies are the hypercomplex algebras, non-orientable surfaces, solitons and breathers, as well as Hopf fibrations of higher dimensional spheres, etc. Recently, Terrence Deacon talks about morphodynamic systems and teleodynamic systems in his work Incomplete Nature. To these we would add sociodynamic systems as names for the emergent levels of organizations represented by the special systems. Deacon discusses what is significant, valuable, functional, and purposive ententional ${ }^{2}$ phenomena within life and consciousness as a result of absential ${ }^{3}$ eventities (defined by Deacon as gaps or holes that appear in nature at the level of teleodynamic systems). Fundamentally, he is making the same points that Heidegger made in Being and Time, long ago, which described Dasein as being-in-the-world, meaning that Dasein cannot be understood either in terms of present-at-hand ways of looking at nature, nor in a ready-to-hand circumspective concern for technological infrastructures that support our lifeworld. Deacon's book Incomplete Nature is a prolegomena for the exploration of Special Systems Theory, which, taken with Being and Time by Heidegger, gives a foundation for understanding what is special about these systems.

Special Systems articulate a meta-theory about the nature of theories that are the anomalous emergent phenomena of Life, Consciousness, and the Social. Each Special System defines the minimal constraints on an emergent threshold in this series that exists between the extremes of the system and the meta-system schemas. Special Systems are partial systems as well as partial meta-systems in different mixtures with different properties. What they tell us is that these anomalous phenomena are organized in a different way than other phenomena based on anomalies in mathematics as well as in physics. Understanding these phenomena (based on analogies with anomalies) is a radical departure for science. Special Systems are a sub-species of Complex Adaptive and Resilient Systems Theory (CARS). They specify a radically limited subset of these Anticipatory Systems (cf. Robert Rosen) as having the characteristics that make the special emergent properties of life, consciousness, and society possible.

\footnotetext{
2 From the Glossary of Incomplete Nature: "A generic adjective ... for describing all phenomena that are intrinsically incomplete in the sense of being in relationship to, constituted by, or organied to achieve something non-intrinsic. This includes function, information, meaning, reference, representation, agency, purpose, sentience, and value."

${ }^{3}$ From glossary of Incomplete Nature: "The paradoxical intrinsic property of existing with respect to something missing, separate, and possibly nonexistent."
} 
A meta-theory Special Systems theory combines other theories that approximate the characteristics of each of these thresholds between the System and the Meta-systems, whose properties are mixed but also separable. The first of these theories is Dissipative Ordering Special Systems Theory pioneered by Ilya Prigogine who produces an image of dissipative structures that achieve negative entropy locally at the expense of the global environment. Terrence Deacon calls these Morphodynamic Systems. These dissipative structures have greater entropy due to the action of the dissipative structure in ordering themselves. In the dissipative structure, order spreads by converting its environment into itself and, as a result, its boundary grows. We call this the Dissipative Ordering (Morphodynamic) Special System. It has a boundary that is expanding and an ordering principle that seems to appear from nowhere as a singularity at the center of the system. It continues to order the background upon which it feeds until it has exhausted the resources of that background and then collapses. It only appears in 'far from equilibrium environments' where there is a source of energy (or material or information), which is flowing in great abundance that produces an edge of chaos supporting localized eddies of negative entropy. However, we also associate this with any projective phenomena and we can use the mobius strip as an example of this super-rationality of the 'local to global relationship' that allows the negative order to exist. In Physics, its analogy is the soliton in a trough. In algebra, we relate it to the Complex Algebra of the Imaginary numbers. Complex numbers lose the unification of the complex conjugates but, for all intents and purposes, the algebra of the complex numbers is equivalent to the algebra of the real numbers, which is very useful to physics. In Hopf fibrations we relate it to the $\boldsymbol{S 1}>$ fibers for $>\boldsymbol{S} \mathbf{3} \boldsymbol{- >} \boldsymbol{S} \mathbf{2}$ transform $^{4}$ between various dimensional spheres. This is a mathematical picture of what Pico calls the reference frame of consciousness. Dissipative ordering flows are assumed to obey the Constructal Law of Adrian Bejan and the Hopf fibrations are the model of the Laminar flow. Bejan posited a reformulation of Thermodynamics in which Flow Architectures remain viable as long as they are approaching incrementally laminar flow. It is assumed in this theory that Dissipative Structures obey this law. In terms of the existentials of Dasein in Being and Time by Heidegger, the dissipative ordering special system is related to the future ecstatic temporal horizon and the existential of Verstehen (understanding) which shows itself in the projection of Dasein. This is the kind of projection that Kant talks about, which gives rise to the synthetic a prioris of Space, Time, and the Categories. We relate this existential to the Conscious temporal reference as it is discussed by Pico. Dissipative Special Systems are also related to the Republic or Ancient Athens imaginary cities of Plato. A dissipative special system can be represented by two mirrors facing each other.

The next emergent threshold is that of the Autopoietic Symbiotic Special System that we related to the existential biological theory of Umberto Maturana and Francisco Varela who attempted to define a biology of the viable living organism rather than the species. Autopoietic Systems are closed (negative information) to outside inspection and fuse living and cognitive characteristics as well as having a stable boundary rather than an expanding boundary like Dissipative Structures. Deacon calls this emergent level of organization that is based on the pairing of mophodynamic

\footnotetext{
${ }^{4}$ It should be noted that morphodynamic systems play both a pre-life role and a post-life role, and the post life role is the dissipative ordering structure of consciousness, and for this reason the Hopf fibrations assigned in an order similar to the assignment of the amicable numbers to the dissipative ordering special systems while the perfect numbers are assigned to the autopoietic symbiotic special system, in other words seemingly out of order. But this is because the autopoietic special system is a conjunction of two dissipative ordering special systems and at the autopoietic level they appear as a synergetic unity in their symbiosis. Similar conditions force us to assign consciousness to the morphdynamic level and thus reverse the way that the specific Hopf fibrations are employed in our explanation of these levels.
} 
systems 'teleodynamic'. It is at this level that absential gaps or holes appear as fundamental missing 'eventities'. Deacon refers to these gaps as ententional. Gilles Deleuze calls them 'floating signifiers' within intersecting series in his Logic of Sense and they appear to play an important role in the functioning of living systems. We can take nested tori as the model of these autopoietic structures. However, we relate the surface of the autopoietic system to the Kleinian Bottle, which globally makes inside and outside indistinguishable. But, we alter the theory of Maturana and Varela based on the structure of the anomalous mathematical and physical analogies to be a conjunction of morphodynamic or dissipative structures. Their relationship to each other is posited to be like that of the soliton 'breather' in which two positive and negative solitons fall into each other using each other as the troughs that each needs. This suggests that the fundamental nature of the autopoietic special system is symbiosis. The autopoietic system is associated with what Pico calls the 'reference frame of Life'. We thus associate it with the Hopf fibration with the $\mathbf{S 3}>$ fibers for $>\mathbf{S 7} \rightarrow \mathbf{S 4}$ transform. But we also associate it with the Quaternions among the hypercomplex algebras and thus with four-dimensional space. Fourdimensional space has some very peculiar properties that are expressed in the Autopoietic Symbiotic Special System made famous through the work of mathematicians Simon Donaldson and Clifford Henry Taubes. Working in differential topology, Taubes proved that fourdimensional space has no set topology but only infinite fake topologies unlike every other dimensional space. Four-dimensional space has perfect motion without singularities as represented by the flows in the 24 cell polytope in the fourth dimension. Four-dimensional space allows all knots to unknot and thus depletes all self-organization as it is represented by the selfinterference of knots with each other, which is the archetype of self-organization. Thus, autopoietic symbiotic systems in three-dimensional space have the property of self-organization because they can be based on the possibility of knotting and unknotting in order to reorganize themselves and thus undergo self-transformation. In four-dimensional space a rotation in the fourth dimension (w axis) is an involution. So, real autopoietic systems contain virtual autopoietic systems and these can involute just like the tesseract ( $4 \mathrm{~d}$ cube, 8 -cell) when rotated. This means that the nested tori in an autopoietic symbiotic system can involute. These nested tori are the Hopf fibration of the hypersphere. This relates to the fact that 'life contains life'. Social Groups (like flocks, schools, swarms of organisms) are living because they contain organisms, and organisms are living because they contain cells. Animal cells are living because they contain mitochondria. The power proto-cells that produce ADT are symbiotic with the host cell. The analogy from physics is the anomaly of Cooper Pairs in superconductivity. This brings us to the point of realizing that Autopoietic systems are ultra-efficacious being a combination of hypereffectivity (agile) and hyper-efficiency (lean). This is made possible by the fact that the autopoietic system is closed and is a series of nested tori, and the nested tori represent a cyclical flow architecture that tends toward laminarity with no resistance. Supercondutivity is also a flow in a circular circuit. Super-conductivity produces very high magnetic fields that can be described by Hopf fibrations. The electromagnetic force was first described by James Clerk Maxwell using Quaternions. Quaternions are non-commutative, therefore, mutual action is asymmetrical in them. Charles Howard Hinton was the first to say that we could think of an electromagnetic flow as a four-dimensional vortex. These vortices are observed on Bose-Einstein condensates as being static but with a winding number around a two-dimensional line singularity. We relate the autopoietic symbiotic special system to the existenital of Befindlichkeit (what is found, state of mind) in Heidegger's Being and Time, which is related to the ecstatic temporal horizon of the Past in which Dasein experiences its 'thrownness' into existence. We find ourselves thrown in the midst of life where we first achieve self-reflexive cognition. We can relate to this to the temporal reference frame of Life as discussed by Pico. Autopoietic systems, according to Maturana and Varella, are simultaneously living and cognitive. The Autopoietic Special System is related to the imaginary city in Plato's Laws (Nomos) called Megara. An autopoieic system can be represented by three mirrors facing each other, which gives a honeycomb structure as seen in a Kaleidoscope. 
According to Deacon Ententional phenomena based on absential eventities arise at this teleodynamic emergent threshold from the interaction of morphodyanmic systems.

The next emergent threshold is the Reflexive Social Special System, which is a conjunction of two Autopoietic Special Systems or four Dissipative Ordering Special Structures. Deacon does not recognize or name these types of special systems, but by following his naming scheme we call this emergent organization sociodynamic and suggest that it is a conjunction of two teleodynamic systems or four morphodynamic systems. Within this even more complex ententional phenomena comprised of abstential eventities can arise that are possible through teleodynamics alone. We relate this level of emergent organization to the field of Reflexive Sociology pioneered by John O'Malley, Barry Sandywell, Alan Blum, Pierre Bourdieu, and others who have looked into the philosophical ramifications of the 'sociology of sociology'. There are a number of reflexive theorists who could be named such as Damjan Bojadziev, Alvin Gouldner, Peter McHugh, Don Kunze, John O'Neill, and Arpad Szakolczai, etc. The prime analogy for the Reflexive Special Sociodynamic System is the Octonions, which is a double cover of the Quaternions thus making four-dimensional space reflexive or extending into eightdimensional space. When you move from the Quaternion algebra to the Octonion algebra the associative property is lost, and that creates the necessity of the social because then it does matter who sits next to whom at the dinner table. Loss of the associative property creates the logical necessity of social relations. Thus, we have the minimum forcing function for the production of social relations. The reflexive social level is associated with the hyper-kleinian bottle, which are two figure-eight (8) Kleinian bottles that share the same circle of self-intersection, and are thus ambiguous not only to the self, but also in their relationship to others. The reflexive special system is also related to the hyper-breather, which is two breathers in relation to each other that are modeled by the 120-cell and 600-cell polytopes in the fourth dimension that contain two intertwined tori. At the Reflexive level there are four mirrors that produce an inwardly mirrored tetrahedron and can be thought of as social mirrors that define the space of social projection as defined by Charles Whitehead. The 120/600 cell polytopes are digital versions of the fourdimensional hypersphere (S3) and thus embody Hopf fibration. We associate this level with the Hopf Fibration that has the $\mathbf{S 0}>$ fibers for $>$ S1 $\rightarrow>$ S1 transform by extending Pico's reference frames so that they have a social reference frame beyond consciousness based on the timings of language synchronization that are based on micro movements. The anomalous physical model of the reflexive system is the Bose Einstein Condensate, which is macro Quantum-Mechanical. We assume that a social space is like the Condensate and contains domain walls. In fact, we assume that the inwardly mirrored tetrahedron is an opaque three-dimensional singularity, which allows the octahedral cells of the lowest energy domain wall configurations to be all space filling. In terms of the existentials of Heidegger in Being and Time, this level is related to Rede or Discourse (talk), which is not associated with any of the normal moments of time. Thus, we related it to the virtual mythic moment of time lost in the transition between the Mythopoietic and Metaphysical eras, which now becomes important when we consider time as multi-dimensional as suggested by J. W. Dunne as discussed in The Serial Universe in 1934 and first hypothesized in 1927. In the Heterochronic era where the assumption of linear or circular time in the Metaphysical era breaks down, the lost fourth mythic moment of time becomes important again to our understanding of existence and we assign it to the existential of Discourse (talk, rede) adumbrated by Heidegger in Being and Time but not assigned to one of the three primary metaphysical moments of time. Since mythos is a story that is a form of discourse, this seems appropriate. The Reflexive Special System is related to the belligerent imaginary city of Atlantis, described in the Critias which was at war with ancient Athens and was eventually destroyed by a catastrophe as discussed by Plato. 
Emergent Meta-system - There is a further emergent level associated with special systems that is a conjunction of a normal system with the three special systems that can produce an emergent meta-system. This is a cycle that contains four operators and four configurations of elements as described by Gottfried Wilhelm von Leibniz in Monadology. This cycle is like a specialization of the Genetic Algorithm and is an extension of the work of Ben Goertzel in his book Chaotic Logic. In a real algebra there are virtual seeds that exist in a pod through which the creation operator becomes a swarm of monads. The real monads that exist in a complex imaginary algebra by a mutual action operator become a constellation of views. The actual views that exist in a quaternion algebra by an operation of schematization becomes a slate of possible candidates. The possible candidates that exist in an octonion algebra through the operation of annihilation (with side effects) becomes a pod of virtual seeds again that exists in a sedenion algebra. Sedenion algebra contains islands of octonions that contain islands of Quaternions that contain islands of complexnions that contain islands of real numbers, so that the bubble of high energy is pushed elsewhere in the potential field and the cycle starts over again. This cycle is trapped in a unique mathematical region created by the Freudenthal-Tits magic square. The hypercomplex algebras also condition the Hopf fibrations that have perfect isometric mappings, which we associate with time. We associate it with the $\mathbf{S 7}>$ fibers for $>\mathbf{S 1 5}->\mathbf{S 8}$ transformation by Hopf fibration which makes the efficacy of the Emergent Meta-system as a temporality possible. The Hopf fibration gives a perfect mapping from S15 to S8 via the fibration of S7 spheres. The Emergent Metasystem as a cultural object can be seen in a very precise model in the oriental game of Go/Wei $\underline{\mathrm{Chi}}$, which is one of the oldest games in the world. One of the few conscious explanations of the structure of the Emergent Meta-system was created by Fa Tsang in his commentary on the Awakening of Faith. The Emergent Meta-system can be related to what Heidegger calls the Mitsein (They, or One) that gives rise to Dasein and is the normative collective to which Dasein belongs. Differentiation from Mitsein is through the realization of Death that causes resoluteness in the face of the inevitability of personal death. Mitsein can be seen as something that fallen Dasein is embroiled within and it can be related to the Greek knowledge known as Metis, which is trickery and cunning as exemplified by Odysseus. Metis is a response to the morass of Contradiction, Paradox, and Absurdity in which Dasein finds itself embroiled in when it encounters Mitsein. Heidegger does not have a positive view of the Social except as Volk.

This is a quick tour of the Special Systems Theory and its relationship to General Schemas Theory as well as the special relationship between Systems and Meta-system schemas that relate to the fourth dimension. In the fourth dimension the Dissipative Ordering (Morphodynamic) Special System relates to the 8-16 cells that are all space filling. The Autopoietic Symbiotic (Teleodynamic) Special System relates to the 24 cell, which has no self-interference to its flows. The Reflexive Social (Sociodynamic) Special System relates to the 12-/600 cell polytopes that contain complementary tori. The Reflexive Social Special System is an image of the hyperbreather embedded in a four-dimensional hypersphere (S3). The Pentachora has the same symmetry as the Icosahedron, which is the group A5 and acts as a hypercycle controller within the virtual autopoietic system embedded in the real autopoietic system. Deacon hypothesizes the AutoGen as a combination of hypercycles with self-assembly to produce protolife through the conjunction of orthograde spontaneous processes within nature. The "AutoGens" is an image of a possible Autopoietic Symbiotic (Teleodynamic) Special System and is a candidate for a hypothesis concerning how life originated. Higher order autogenetic structures are called "Teleogens" but the fact that there is an even higher threshold of negative entropic absential organization that could be called "SocioGen" is not recognized by Deacon.

The various analogies of Special Systems Theory merely constrain the potential emergence of Special Systems in nature with their unique and peculiar properties and makes them possible as anomalous special conjunctions of elements that support Life, Consciousness, and the Social. 
They are emergent phenomenal levels based on special reference frames that define living, conscious, and social reference frames that imply other timelines beyond an entropic 'time arrow' of physical nature captured by the System and Meta-system schemas and the rest of the schemas of the $S^{\prime}$ (prime schema hypothesis) projection of the spacetime relativistic reference frame. The physical anomalies with special properties embodied in solitons, breathers, and hyper-breathers as well as super-conductivity and Bose-Einstein condensates, make this a scientific theory that has not only a mathematical basis, but also a basis in actual anomalous physical phenomena that demonstrates that the mathematical analogies have parallels in objective physical reality. And we know this from the fact that we are living social creatures who are intrinsically social and it is this feature that cause systems to be actualizable. Special Systems theory shows why we can have those physical characteristics and it can be used to explain other more mundane phenomena, for example, Agile and Lean team work systems. It is important to relate the insights of Deacon in Incomplete Nature to the fundamental ontology of Heidegger in Being and Time in order to see that the structures of ententional phenomena are rooted in Dasein's being-in-the-world and its existentials and temporality. Deacon has given a present-at-hand rendition of what Deleuze in Logic of Sense calls "floating signifiers" within intersecting series. But this set-like approach needs to be related to the mass-like approach to experience that Heidegger calls the ready-to-hand that explains how references become related to totalities. But, we must also explain the fundamental interpretive nature of life that makes sense of sensations in terms of the nature of Dasein itself, which is prior to the arising of Subject and Object made possible by pointing and even the technological infrastructure that supports action in the world (which is related to grasping). The present-at-hand is an image of what Aristotle calls the epistemic knowledge of science that is fundamentally distanced from phenomena, i.e., objective (or not distanced, i.e., subjective). Present-at-hand epistemic knowledge relates to the representable intelligibles that are related to Ratio on Plato's Divided Line. The ready-to-hand is Aristotle's image of the kind of knowledge that is understood through skill and craft. It is described as the techne of poiesis. Ready-to-hand circumspective concern of Dasein is related to the grounded opinion and appearances of doxa on Plato's Divided Line. But according to recent interpretations of Being and Time, Dasein is an image of Phronesis or Judgment, which is a kind of knowledge that allows one to deal with ungrounded opinion and appearances on Plato's Divided Line. This is apropos because Judgment is the core faculty that Kant considers to be the basis of Reason from which he derives the ontological categories. This relates to physical objects that are known to science based on the projection a priori synthesis of Space, Time, and the Categories. Dasein is the projective function of the human being known to Kant as the Transcendental Subject of apperception, which is the dual of the Noumena (Transcendental Object). Heidegger works out the internal structure of Dasein by a form of prescission (cf C. Peirce) in which the whole is articulated but not dissected. This structure is related to the four timelines that appear in the heterochronic era once the mythic moment is recognized as being significant for our understanding of social time. And these four temporal reference frames (three of which are recognized by Pico) can be added to the social timeline. They are related to the four existentials of Dasein posited by Heidegger, one of which is not mapped to a moment of time in Being and Time. Understanding that there are four dimensions of time, and that they intersect in the human being as Dasein, being-in-the-world, as a mapping to four moments of time which in turn are related to the existentials of Dasein is an important step for grounding the ententional present-at-hand understanding of absential phenomena that Deacon describes. This understanding of the ecstasies of temporality is key to our understanding of Morphodynamics, Teleodyanmics and Sociodyanmics of Life, Consciousness, and the Social that are fused in our existential Being. We can see an image of this fusion represented by the Pascal Triangle that merges the different characteristics of the Special Systems into a singular mathematical formation. 
Special Systems theory is not a series of analogies that just happen to dovetail into a theory of the mathematical constraints on the possibilities of life, consciousness, and the social. Special Systems theory has theoretical depth based on the rethinking of fundamental concepts from physics as described by Deacon, as well as the grounding that Rosen describes in Life Itself in the categorical analysis of causality and inference. But also it harkens back to Heidegger's answer to Einsteinan Relativity Theory by showing that physical models that assume space-time fusion of the type posited by Georg Wilhelm Friedrich Hegel must have a grounding in the existenital temporalities of life via befindlichkeit (foundness) as it relates to the past through thrownness, consciousness via verstehen (understanding) related to the future through projection, and the social via rede (talk, discourse) through the mythic moment. In this model from Being and Time each of these existentials have a degenerate mode of idle-talk, curiosity, and ambiguity that are related to the existential of Fallenness, which is related to the present. The present (which is the now that is eternal thermodynamics) is brought to bear on everything and causes these other temporalities to degenerate and lose their own unity. It is because of the nature of the Hopf fibrations that time is able to escape the machinations of thermodyanmics and this kink in the structure of mathematics allows the proliferation of these separate temporal reference frames. Thus, the production of the emergent structures of life, consciousness, and the social through what Deacon calls the arising of morphodyanmics, teleodyanmics, and also what I call reflexive sociodynamics. These are all special systems with special properties dictated by the inherent and intrinsic structure of mathematics and physics that provide the constraints that Deacon discusses as the fundamental prerequisites for the arising ententional abstential phenomena, which are utterly mysterious from the point of view of Science and its reduction of everything to the present-at-hand mode of apprehension of Dasein.

Archer, Margaret S. The Reflexive Imperative in Late Modernity. New York: Cambridge University Press, 2012.

Ashmore, Malcolm. The Reflexive Thesis: Wrighting Sociology of Scientific Knowledge. Chicago: University of Chicago Press, 1989.

Barnouw, Jeffrey. Odysseus, Hero of Practical Intelligence: Deliberation and Signs in Homer's Odyssey. Lanham, Md: University Press of America, 2004.

Bejan, Adrian, and J P. Zane. Design in Nature: How the Constructal Law Governs Evolution in Biology, Physics, Technology, and Social Organization. New York: Doubleday, 2012.

Bejan, Adrian. Shape and Structure, from Engineering to Nature. New York: Cambridge University Press, 2000.

Blum, Alan F. Socrates, the Original and Its Images. London: Routledge and K. Paul, 1978.

Blum, Alan F. Theorizing. London: Heinemann, 1974.

Blum, Alan, and Peter McHugh. Friends, Enemies, and Strangers: Theorizing in Art, Science, and Everyday Life. Norwood, N.J: Ablex Pub. Corp, 1979.

Bojadziev, Damjan. "Dimensions of Self-Representation." Informacijska Druzba Is'99. (1999): 67-71.

Bojadziev, Damjan. "Forms of Reflection." Zbornik 8. Mednarodne Multikonference Informacijska Druzba Is 2005, 11. Do 17. Oktober 2005. (2005): 5-8

Bojadziev, Damjan. "Self-reference in Arithmetical and Natural Language." Linguistische Arbeiten. (1993): 491-496.

Bourdieu, Pierre, and Loic J. D. Wacquant. An Invitation to Reflexive Sociology. Chicago: University of Chicago Press, 1992.

Bourdieu, Pierre. In Other Words: Essays Towards a Reflexive Sociology. Cambridge: Polity, 1990.

Bowler, Michael J. Heidegger and Aristotle: Philosophy As Praxis. London: Continuum, 2008.

Capra, Fritjof. The Web of Life: A New Synthesis of Mind and Matter. London: Flamingo, 1997.

Cook, Francis H. Hua-yen Buddhism: The Jewel Net of Indra. University Park: Pennsylvania State University Press, 1977.

Coutu, Walter. Emergent Human Nature: A Symbolic Field Interpretation. New York: A.A. Knopf, 1949.

Cybernetics \& Human Knowing: A Journal of Second-Order Cybernetics, Autopoiesis and Cyber-Semiotics. Thorveton (PO Box 1, Thorveton EX5 5YX: Imprint Academic, 1992.

Deacon, Terrence W. Incomplete Nature: How Mind Emerged from Matter. New York: W.W. Norton \& Co, 2012.

Deleuze, Gilles. Difference and Repetition. New York: Columbia University Press, 1994.

Deleuze, Gilles. The Logic of Sense. New York: Columbia University Press, 1990.

Detienne, Marcel, and Jean-Pierre Vernant. Cunning Intelligence in Greek Culture and Society. Hassocks [Eng.: Harvester Press, 1978.

Donaldson, Simon K, and P B. Kronheimer. The Geometry of Four-Manifolds. Oxford: Clarendon Pr, 1990.

Doueihi, Milad. The Metis of the Greeks. Baltimore, MA: Johns Hopkins University Press, 1986.

Dunne, J W. An Experiment with Time. New York: The Macmillan Company, 1927.

Dunne, J W. The Serial Universe. New York: Macmillan Co, 1938.

Eco, Umberto. Kant and the Platypus: Essays on Language and Cognition. New York: Harcourt Brace, 2000

Fa Tsang (Fazang), . An English Translation of Fa-Tsang's Commentary on the Awakening of Faith. Lewiston, N.Y: Edwin Mellen Press, 2004.

Fleischaker, Gail R. Autopoiesis: System Logic and Origins of Life. Ann Arbor, Mich: University Microfilms International, 1990.

Flyvbjerg, Bent, Todd Landman, and Sanford Schram. Real Social Science: Applied Phronesis. Cambridge: Cambridge University Press, 2012. 
Fraenkel, Abraham A. Extension of the Number-Concept: Groups and Fields. Rational, Real, Complex, Hypercomplex Numbers. New York: Scripta Mathematica, Yeshiva University, 1964

Geyer, R F, and J . Zouwen. Sociocybernetics: Complexity, Autopoiesis, and Observation of Social Systems. Westport, Conn: Greenwood Press, 2001.

Goertzel, Ben. Chaotic Logic: Language, Thought, and Reality from the Perspective of Complex Systems Science. New York: Plenum Press, 1994

Gouldner, Alvin W. The Coming Crisis of Western Sociology. New York: Basic Books, 1970.

Hanson, Andrew. Visualizing Quaternions. San Francisco, CA: Morgan Kaufmann, 2006

Haugeland, John, and Joseph Rouse. Dasein Disclosed: John Haugeland's Heidegger. Cambridge, Mass: Harvard University Press, 2013.

Heidegger, Martin. Being and Time. New York: Harper, 1962.

Heidegger, Martin. Phenomenological Interpretations of Aristotle: Initiation into Phenomenological Research. Bloomington, IN: Indiana University Press, 2001.

Heidegger, Martin. Plato's Sophist. Bloomington, Ind: Indiana University Press, 1997.

Hess, Adrien L. Four-dimensional Geometry: An Introduction. Reston, Va: National Council of Teachers of Mathematics, 1977.

Hinton, Charles H, and Rudy B. Rucker. Speculations on the Fourth Dimension: Selected Writings of Charles H. Hinton. New York: Dover Publications, 1980.

Hinton, Charles H. The Fourth Dimension. London: Sonnenschein, 1904.

Kantor, I L, and A S. Solodovnikov. Hypercomplex Numbers: An Elementary Introduction to Algebras. New York: Springer-Verlag, 1989.

Kauffman, Stuart A. At Home in the Universe: The Search for Laws of Self-Organization and Complexity. New York: Oxford University Press, 1995.

Kauffman, Stuart A. Investigations. Oxford: Oxford University Press, 2000.

Kauffman, Stuart A. The Origins of Order: Self-organization and Selection in Evolution. New York: Oxford University Press, 1993.

Lash, Scott. Another Modernity, a Different Rationality. Oxford UK: Blackwell Publishers, 1999.

Latour, Bruno. Reassembling the Social: An Introduction to Actor-Network-Theory. Oxford: Oxford University Press, 2005.

Leibniz, Gottfried W, and Robert Latta. The Monadology. Raleigh, N.C: Alex Catalogue, 1990

Liu, Ming-Wood. The Teaching of Fa-Tsang: An Examination of Buddhist Metaphysics. , 1980.

Manning, Henry P. Geometry of Four Dimensions. New York: Dover Publications, 1956.

Maturana, Humberto R, and Francisco J. Varela. The Tree of Knowledge: The Biological Roots of Human Understanding. Boston: Shambhala, 1992.

Maturana, Humberto R, Humberto R. Maturana, and Francisco J. Varela. Autopoiesis and Cognition: The Realization of the Living. Dordrecht, Holland: D. Reidel Pub. Co, 1980.

McHugh, Peter. Defining the Situation: The Organization of Meaning in Social Interaction. Indianapolis: Bobbs-Merrill, 1968.

McHugh, Peter. On the Beginning of Social Inquiry. London: Routledge and Kegan Paul, 1974.

McMullin, Barry. Autopoiesis and Perception. Dublin City University, School of Electronic Engineering, 1994.

McNeill, William. The Glance of the Eye: Heidegger, Aristotle, and the Ends of Theory. Albany: State University of New York Press, 1999.

Mingers, John. Self-producing Systems: Implications and Applications of Autopoiesis. New York: Plenum Press, 1995.

Olafson, Frederick A. Heidegger and the Ground of Ethics: A Study of Mitsein. Cambridge, UK: Cambridge University Press, 1998.

O'Malley, John B. Sociology of Meaning. London: Human Context Books, 1972.

O'Neill, John. Sociology As a Skin Trade: Essays Towards a Reflexive Sociology. New York: Harper \& Row, 1972.

Palmer, Kent. Agile Theory (manuscript 2012)

Palmer, Kent. Emergent Design (2009) U. South Australia Ph.D. dissertation.

Palmer, Kent. Lean Agile Scaling (manuscript 2013)

Palmer, Kent. Lean Agile Systems Engineering (manuscript 2013)

Palmer, Kent. Reflexive Autopoietic Dissipative Special Systems Theory (2000)

Palmer, Kent. Reflexive Autopoietic Systems Theory (2000)

Palmer, Kent. The Foundations of Agile Teamwork (manuscript 2013)

Palmer, Kent. The Fragmentation of Being and the Path Beyond the Void (1994)

Palmer, Kent. The Structure of Theoretical Systems in Relation to Emergence (1982) London School of Economics, University of London, Ph.D. dissertation.

Palmer, Kent. Wild Software Meta-systems (1996)

Phillips, James. Heidegger's Volk: Between National Socialism and Poetry. Stanford, Calif: Stanford University Press, 2005.

Plato, , and Francis M. Cornford. The Republic of Plato. London: Oxford University Press, 1945.

Plato, , and Thomas L. Pangle. The Laws of Plato. New York: Basic Books, 1980.

Plato, , Plato, Plato, and H D. P. Lee. Timaeus and Critas. Harmondsworth: Penguin, 1971.

Prigogine, I, and Isabelle Stengers. The End of Certainty: Time, Chaos, and the New Laws of Nature. New York: Free Press, 1997.

Prigogine, I, Isabelle Stengers, and I Prigogine. Order Out of Chaos: Man's New Dialogue with Nature. Toronto: Bantam Books, 1984.

Prigogine, I. From Being to Becoming: Time and Complexity in the Physical Sciences. San Francisco: W.H. Freeman, 1980.

Prigogine, I. Introduction to Thermodynamics of Irreversible Processes. New York: Interscience Publishers, 1968.

Rosen, Robert, Judith Rosen, John J. Kineman, and Mihai Nadin. Anticipatory Systems: Philosophical, Mathematical, and Methodological Foundations. New York: Springer, 2012

Rosen, Robert. Life Itself: A Comprehensive Inquiry into the Nature, Origin, and Fabrication of Life. New York: Columbia University Press, 1991.

Sadler, Ted. Heidegger and Aristotle: The Question of Being. London: Athlone, 1996.

Sandywell, Barry. Presocratic Reflexivity: The Construction of Philosophical Discourse C. 600-450 Bc. London: Routledge, 1996.

Sandywell, Barry. Problems of Reflexivity and Dialectics in Sociological Inquiry: Language Theorizing Difference. London: Routledge \& K. Paul, 1975.

Sandywell, Barry. Reflexivity and the Crisis of Western Reason. New York: Routledge, 1996.

Sandywell, Barry. The Beginnings of European Theorizing-Reflexivity in the Archaic Age. London: Routledge, 1996. 
Scorpan, Alexandru. The Wild World of 4-Manifolds. Providence, R.I: American Mathematical Society, 2005

Starr, David E. Entity and Existence: An Ontological Investigation of Aristotle and Heidegger. New York: B. Franklin, 1975.

Susen, Simon. The Foundations of the Social: Between Critical Theory and Reflexive Sociology. Oxford: Bardwell Press, 2007.

Szakolczai, A'rpa'd. Reflexive Historical Sociology. London: Routledge, 2000.

Thiele, Leslie P. The Heart of Judgment: Practical Wisdom, Neuroscience, and Narrative. New York: Cambridge University Press, 2006.

Varela, Francisco J, Evan Thompson, and Eleanor Rosch. The Embodied Mind: Cognitive Science and Human Experience. Cambridge, Mass: MIT Press, 1991.

Whitehead, Charles. Social Mirrors And The Brain: including a functional imaging study of role-play and verse, PhD Thesis Department of Anthropology University College London, 2003

Woolgar, Steve. Knowledge and Reflexivity: New Frontiers in the Sociology of Knowledge. London: Sage, 1988.

Zeleny, Milan. Autopoiesis, a Theory of Living Organizations. New York, N.Y: North Holland, 1981.

Zeleny, Milan. Autopoiesis, Dissipative Structures, and Spontaneous Social Orders. Boulder, Colo: Westview Press, 1980. 